\title{
Perfis de Adolescentes Mães Após Três Anos e Meio do Nascimento do Bebê: Seguimento Longitudinal de Estudo Psicossocial
}

\author{
Nancy Ramacciotti de Oliveira-Monteiro \\ Universidade Federal de São Paulo
}

\begin{abstract}
RESUMO
Neste artigo são apresentados resultados de investigação psicossocial longitudinal sobre maternidade de adolescentes pobres de cidades paulistas. $\mathrm{O}$ estudo pesquisou condições psicossociais associadas à gravidez na adolescência, em dois momentos: (1) nos primeiros meses após o parto e (2) cerca de quatro anos após o parto. A pesquisa fez uso de entrevistas em profundidade, realizadas nas próprias moradias. As jovens indicavam se perceber como as principais responsáveis pela criação das crianças e não pareciam entender a maternidade de forma negativa. Prejuízos na vida escolar foram aprofundados especialmente por constantes mudanças de moradia. A proximidade de riscos sociais associados à pobreza e aos seus ambientes cotidianos, foi apresentada como integrante de suas vidas. As crianças foram valorizadas, mas referidas como motivo de impedimentos para a disponibilidade para lazer. Os filhos pareciam protegê-las de maior exposição frente a algumas situações de risco (drogas).
\end{abstract}

Palavras-chave: gravidez na adolescência; maternidade de adolescentes pobres; fatores de risco e proteção; estudo longitudinal.

\section{ABSTRACT \\ Profiles of Adolescent Mothers Three Years Time After Childbirth: Continuation of a Psychosocial Study}

This article presents the results of a longitudinal psychosocial investigation about adolescent motherhood among poor teenagers in the State of São Paulo. This study has researched psychosocial conditions associated to teenage pregnancy at two time points: (1) in the initial months after childbirth; (2) approximately four years after childbirth. The research included open-ended interviews, performed at home. These young mothers indicated that they were responsible for raising their children, and they did not perceive motherhood in a negative manner. Their educational setbacks had increased, particularly due to the recurring changes of address. The perception of the proximity of social risks associated with their living in poor environments was expressed as being common. Mothers valued their children, although they reported that the children interfered with their leisure time. Having children appeared to protect mothers from exposure to other risky behaviors such as drug use.

Keywords: teenage pregnancy; motherhood among poor teenagers; risk and protection factors; longitudinal study.

Desde as últimas décadas do século XX, organismos nacionais e internacionais têm considerado a gravidez na adolescência como preocupante, pela vulnerabilidade associada à saúde e desenvolvimento social futuro das adolescentes e de seus filhos. A gravidez na adolescência é tida não apenas como um problema específico de saúde dentro do ciclo gravídico-puerperal, mas também como uma ameaça ao futuro da jovem e do jovem, por prováveis riscos físicos, emocionais e sociais dela decorrentes (Cannon, 1998).
Fatores de risco e de proteção relacionados à gravidez de adolescentes, em especial de adolescentes pobres, são tidos a partir de naturezas temporais diferentes. Aqueles riscos chamados de "curto prazo" relacionam-se especificamente ao período da gestação, a partos e pós-partos imediatos, e a abortos, muitas vezes realizados em condições precárias. Dessa forma, a qualidade e especialidade do pré-natal e dos serviços de maternidade constituem-se fatores que visam à proteção da saúde da mãe adolescente e de 
seu filho. Já um grupo de possíveis riscos, entendidos como de "longo prazo", relacionam-se à vida futura da adolescente ou do casal adolescente, e também de sua descendência. Riscos de menor chance de completar a escolaridade com consequente redução de oportunidades de trabalho, construção de famílias numerosas e separações, riscos maiores dos filhos adoecerem, sofrerem acidentes e de apresentar baixo desempenho escolar são tidos como prováveis consequências negativas da gravidez de adolescentes (Cannon, 1998), principalmente das mais pobres. Nessa dimensão, fatores de risco e fatores de proteção são mais complexos de serem avaliados no tocante ao desenrolar da vida de jovens a partir do evento da gravidez ocorrida na adolescência.

Questionamentos sobre prováveis consequências negativas da gravidez de adolescentes têm sido apresentados em recentes trabalhos brasileiros. Ao afirmar e discutir a heterogeneidade do fenômeno em diferentes condições sociais, esses estudos têm contribuído para relativizar o entendimento de que a maternidade adolescente traga inevitáveis repercussões negativas, no tocante à trajetória de vida da mãe adolescente (Amazarray, Machado, Oliveira \& Gomes, 1998; Aquino e cols., 2003; Borges \& Schor, 2005; Esteves \& Menandro, 2005; Santos \& Schor, 2003).

Neste artigo apresentam-se dados longitudinais no acompanhamento de jovens que foram mães na adolescência, a partir de estudos que investigaram seus perfis psicossociais em dois momentos: quando seus filhos tinham de um a quatro meses, e quando estavam com quase quatro anos (idades entre três anos e quatro meses e três anos e 10 meses). A proposta de um estudo longitudinal procurou contribuir com a ampliação do conhecimento acerca de repercussões da gravidez de adolescentes em condições socioeconômicas características de periferias sociais e urbanas de centros metropolitanos.

\section{Perfis psicossociais de mães adolescentes com filhos menores de cinco meses}

Foram investigadas 10 adolescentes, de 15 a 16 anos, primíparas, usuárias de um serviço público especializado em pré-natal e maternidade de adolescentes da Baixada Santista (região metropolitana no litoral do Estado São Paulo), através de entrevistas de discurso livre, numa associação das propostas de Bleger (1998) e Rodrigues (1978), que propunha o tema "falar sobre suas vidas"; as entrevistas foram realizadas e gravadas nas próprias moradias das mães adolescentes que tinham bebês menores de cinco meses. Durante cerca de um mês, ocorreram pelo menos quatro visitas para cada adolescente: uma visita para a proposta da pesquisa e mais três visitas para as entrevistas. Por vezes foram necessárias mais visitas já que algumas das investigadas haviam mudado de residência, de bairro e até de cidade.

De forma geral, as 10 adolescentes mães pesquisadas não indicaram avaliar a gravidez e a maternidade como experiências marcadas com um sentido de risco, perda ou fracasso. Pertencentes a segmentos pobres da população, próximas a diferentes situações de riscos sociais e com dificuldades relativas às suas expectativas de futuro, elas pareciam dar à gravidez e maternidade de um bebê pequeno um significado de conquista, com uma ideia de que estavam paradoxalmente menos fracas e também de que seriam mais protegidas. De forma semelhante, o estudo de Carvalho (2007) com jovens moradores de uma favela de São Paulo (SP) indicou que a maternidade (e também a aparência física da gravidez) aumentava o status social e que os jovens não retratavam a gravidez adolescente como um problema social e de saúde.

Para as 10 pesquisadas, a gravidez pareceu conscientemente procurada, ou fruto de uma posição passiva e receptiva para engravidar. As adolescentes deram referências de que buscavam constituir uma família, com um bebê, um companheiro e uma casa. Quando três delas, em parte, frustraram-se nessas expectativas, porque os pais dos bebês não se prestavam a assumir papéis de maridos e companheiros, elas os impediram de registrarem e terem contato com as crianças, que ficaram sem o nome do pai na certidão de nascimento.

Nos ambientes sociais das adolescentes estudadas, a gravidez na adolescência causou manifestação inicial de crítica e repúdio que em geral evoluiu para aceitação, durante o desenvolvimento da gravidez até o nascimento do bebê. Essa aceitação nunca indicava alterar a referência de desconsideração social (também delas próprias) frente à gravidez na adolescência. Em todos os casos estudados houve manifestação de julgamentos negativos por elas terem engravidado naquela idade. As condenações relacionavam-se à ocorrência da concepção (por descuidos na utilização de métodos contraceptivos) e não se referiam a uma condenação diante da vida sexual ativa das adolescentes e de seus pares.

Para as adolescentes estudadas, a maternidade indicava um significado de salto para um status mais adulto. Elas referiam seguidamente a perda de liber- 
dade em contraposição à aquisição da responsabilidade (como ressaltado por Esteves \& Menandro, 2005), atributo novo a ser, ou sendo, incorporado. Considere-se que essa perda de disponibilidade para o lazer referia-se a impedimentos de ida a alguns bailes e shows. A maternidade representava limites para a liberdade de sair (para "zoar"), mas também parecia trazer compensações. A gravidez e o nascimento do bebê traziam um período de aumento na recepção de atenção, visitas e presentes ou doações de enxoval e enfeites para a criança, material com forte apelo lúdico.

Ganhos afetivos, como companhia na solidão, eram referidos (como em Amazarray e cols., 1998) e também alguns ganhos materiais. Os pertences do bebê, e principalmente o próprio bebê pequeno, eram ganhos visíveis que se contrapunham à demanda de trabalho com a criança - um trabalho mais ou menos conhecido, já que várias das adolescentes pesquisadas cuidavam de seus irmãos ou sobrinhos mais novos antes de terem um bebê "seu".

Possibilidades de prejuízos escolares foram pouco referidos nos relatos das entrevistadas. As adolescentes pesquisadas engravidaram já estando numa relação de conflito com a escola, ou mesmo fora dela (como em Aquino e cols., 2003). Elas apresentavam especial dificuldade em se imaginar no futuro, além de constantes dificuldades nas localizações temporais quanto ao passado, mesmo mais recente. Esse dado veio ao encontro do indicado por Knobel (1988) quanto às dificuldades de localização temporal de adolescentes. Planos, projetos e temores de possíveis problemas ou de prejuízos advindos da maternidade ocorrida na adolescência ficaram, assim, pouco expressados nessa etapa do estudo, quando as mães estavam com 15 ou 16 anos e seus filhos ainda eram bem pequenos.

\section{Perfis psicossociais dessas mães após cerca de quatro anos da ocorrência da gravidez na adolescência}

Após cerca de três anos e meio foram novamente realizadas entrevistas de discurso livre sobre suas vidas, gravadas nas próprias moradias, com oito das 10 mães que já tinham sido entrevistadas quando seus filhos estavam com menos de cinco meses. $\mathrm{O}$ encontro das pesquisadas foi dificultado pela característica de grande mobilidade na situação de moradias. A seleção das oito entrevistadas ocorreu pela possibilidade do reencontro. Elas estavam com idades entre 18 a 20 anos e aceitaram prontamente e de forma interessada a continuidade de participação na pesquisa ${ }^{1}$.
Quase todos os relatos presentes nessa etapa do estudo foram marcados por temas sobre a luta pela sobrevivência - para cuidar da vida como podiam. Referências sobre várias mudanças de moradia e sobre vicissitudes das ligações amorosas e familiares ficaram mais frequentemente associadas com inseguranças vinculadas ao tráfico de drogas e à criminalidade dos ambientes de moradia.

Além de dificuldade de "enraizamento" social decorrente das instabilidades causadas pelas mudanças de endereço, houve em todos os depoimentos um fator comum relativo à dificuldade de pertinência a instituições escolares ou sociais (clubes, associações, igrejas). As entrevistadas, em geral, cuidavam das crianças em suas casas, tendo feito poucas e fracassadas voltas à escola, além de algumas tentativas esporádicas de inserção no mercado profissional. Havia dificuldades de inserção das crianças em creches, fosse por falta de vagas ou mesmo falta de procura desse serviço.

A experiência da maternidade ocorrida na adolescência mereceu considerações positivas, diretas ou indiretas, em todos os casos pesquisados. Essa valorização ficou claramente relacionada à experiência concreta com a criança, para companhia e como propriedade (afetiva) disponível.

As avaliações negativas, relacionadas à prejuízos causados pela gravidez e maternidade ocorridas na adolescência, novamente receberam destaques associados à perda de lazer, especialmente o lazer oferecido em ocasiões de maior soltura social, com menores restrições para se "zoar" (desfrutar de bailes e das diversões noturnas). As avaliações negativas não ressaltaram os obstáculos ao desenvolvimento escolar ou profissional, provenientes ou agravados pela situação da maternidade ocorrida na adolescência.

Nesse momento da pesquisa, referências relativas ao tempo futuro de suas vidas foram mais citadas. Os projetos e expectativas referidos nos depoimentos das entrevistadas estavam principalmente voltados às necessidades materiais, ressaltando-se as necessidades de maior segurança quanto à moradia. Ter uma casa, especialmente uma casa própria, foi um desejo muito evocado. Referências de projetos de terminar estudos (sem identificação ou delimitação do limite do término) e conseguir um bom emprego, também foram frequentes nos relatos. Os projetos de ter outro filho estiveram presentes nas sondagens com cinco das oito entrevistadas - aquelas cinco que ainda não tinham um segundo filho. 


\section{ANÁLISES E DISCUSSÃO DE DADOS DA SEQUÊNCIA LONGITUDINAL}

Os dados referentes ao primeiro momento do estudo refletiam condições limitadas ao tempo da gravidez e do bebê bem pequeno. Nessas condições, os possíveis "riscos de curto prazo", aqueles associados ao ciclo gravídico-puerperal, estavam relativamente controlados pela adesão das jovens ao pré-natal especializado, que incluía atenção psicológica e social à adolescente, à sua família e ao pai do bebê, além do acompanhamento obstétrico e fisioterápico. Já os dados referentes à segunda etapa da investigação não estavam mais diretamente associados a essas possíveis condições de proteção associadas ao ciclo da gravidez, parto e puerpério.

Fatores socioeconômicos que caracterizam risco social, especialmente aqueles ligados a condições de pobreza (falta de segurança, conforto e higiene) foram indicados em quase todos os casos estudados. As oito entrevistadas (nos dois momentos) não dispunham de condições de alguma autonomia econômica, dependendo de suas famílias ou de seus companheiros.

Uma boa inserção escolar, como fator de proteção ao desenvolvimento das jovens, também não se traduziu em nenhum dos casos. As histórias de trajetória escolar traziam uma marca de insucesso em sete das oito investigadas, mas todas manifestaram o valor social dos estudos. O fracasso escolar, entretanto, não foi referido como fracasso pessoal. Nos dois momentos do estudo, as entrevistadas pareciam entender que não estudavam, ou não tinham estudado, por opção delas mesmas, conseguindo fazer poucas avaliações críticas que incluíssem dificuldades relativas à condição de maternidade, ou dificuldades sociais, impeditivas ou prejudiciais a seus desenvolvimentos escolares.

Em todos os casos, as dificuldades e impedimentos referentes à trajetória escolar pareceram agravados pela condição de indisponibilidade causada pela necessidade de cuidado dos filhos, não tendo com quem os deixar. Como referido por Esteves e Menandro (2005), a maternidade cria mecanismos de geração de responsabilidade, e aumenta as restrições relativas à disponibilidade do próprio tempo. Entretanto, sobremaneira, foram as mudanças de moradia (que incluíam mudanças de bairros e até de cidades, ocorridas após o nascimento da criança) que se ressaltaram como os maiores obstáculos para desenvolvimento nos estudos, considerando as dificuldades de matrículas e transferências escolares, especialmente as fora do calendário escolar. Todas as providências a serem tomadas para nova inclusão na escola pareciam ter ficado delegadas somente às entrevistadas, desde quando elas tinham engravidado.

As entrevistadas indicaram que, a partir da maternidade, passaram a ser menos tratadas, ou identificadas, como filhas, num sentido em que mais declaradamente se delegava a elas a responsabilidade da luta pela sobrevivência, ou pelas suas inserções escolares e profissionais. Mesmo as famílias que pareciam dar apoio, por proximidade e disponibilidade para ajudar, ficaram sugeridas como entendendo a condição daquelas jovens mães, como principais responsáveis pela própria vida e a de seus filhos.

Todas as entrevistadas, especialmente no segundo momento do estudo, referiram ou sugeriram situações de risco relacionadas principalmente com: tráfico e uso abusivo de drogas (de vizinhos e/ou de familiares), violência urbana e criminalidade (com comentários sobre roubos, ameaças e juramentos de morte seguidos de fugas; mortes com crueldade), prostituição, abuso sexual e violência doméstica. As referências dessas situações foram tratadas, por vezes, de forma banalizada, como fazendo parte de um cotidiano, um ambiente familiar com o qual se convive. Os relatos das entrevistadas indicavam que elas não faziam uso de entorpecentes. As exigências relativas ao cuidado da criança, e o próprio vínculo com ela, pareciam distanciar as mães do envolvimento direto (por uso e/ou tráfico) com drogas.

A manutenção ou restauro de vínculos amorosos e de pertinência nas famílias (expressos na frequência de contatos e nos gestos de apoio, mesmo breves ou descontínuos) pareceu o principal diferencial para uma condição de melhor proteção diante de riscos mais graves nos contextos de vida das entrevistadas. Três dos casos estudados apresentaram ligações mais danificadas com as famílias de origem. Essas entrevistadas foram as que indicaram estar gravemente vulneráveis a riscos, principalmente de violência, drogas, criminalidade e prostituição. Situações de riscos psicossociais envolvidos de forma mais direta com algumas das entrevistadas (prostituição, surto psiquiátrico, violência, delinquência e tráfico) ocorreram em casos onde havia maior prejuízo na inserção familiar, como nas situações de abandono, precariedade, turbulência e danificação. Nos casos em que a relação com a família de origem apresentava-se melhor instalada, com maior segurança e confiança nos vínculos, os riscos apresentados foram principalmente relacionados ao ambiente em que as entrevistadas moravam em bairros pobres e com graves problemas 
de segurança. Esses riscos pareceram mais administráveis, já que diante deles, elas indicavam alguma articulação nas estratégias para convivência, esquiva ou proteção.

Nos dois momentos do estudo, as entrevistadas indicaram pouco desenvolvimento nos contatos de amizades, com indícios de desconfiança de colegas do mesmo sexo e de idades próximas. A carência ou empobrecimento de contatos de amizade provavelmente estava relacionado com a saída da escola e a não pertinência em grupos de lazer. Restavam algumas amizades na vizinhança, em geral a de moças também mães, mas o contato parecia pouco estimulante ou valorizado.

Nenhuma das entrevistadas relatou inserção em grupos esportivos ou culturais, a partir da ocorrência da gravidez na adolescência; somente uma das entrevistadas referiu uma experiência passageira num grupo de teatro. As atividades de lazer pareceram bastante restritas, resumindo-se a alguns passeios de final de semana. Como já colocado, a falta de oportunidade para atividades mais descompromissadas, como nas diversões noturnas, nos bailes e bares, foi lamentada e entendida por algumas entrevistadas como o principal prejuízo que haviam tido com a gravidez e o nascimento do bebê.

As atividades do cotidiano aconteciam em geral dentro do campo doméstico (como nas tarefas da casa, incluindo cuidar dos filhos e dos companheiros, e ver televisão) e nos serviços esporádicos que tinham (ou em sua procura). A descrição desse cotidiano foi tonalizada com um espírito de dificuldades, com buscas e lutas pela sobrevivência ou com desânimo ou desesperança diante da vida.

O segundo momento da sequência do estudo indicou que todas as entrevistadas tinham dificuldades na inserção profissional. Sobre trabalho, os relatos foram depoimentos referentes a tentativas, em geral rápidas e fracassadas dentro de um repertório muito restrito de oportunidades, como atividades de panfletagem (aumentadas na época de campanhas políticas), empregos como empregadas domésticas e de serviços gerais. Quase nunca as entrevistadas tiveram registro de seus serviços.

Também em relação à segunda etapa do estudo: as crianças pareciam desenvolver-se sem perceptíveis problemas de saúde e foram bastante valorizadas nos depoimentos (de forma semelhante ao encontrado por Amazarray e cols., 1998; Esteves \& Menandro, 2005; Santos \& Schor, 2003). O exercício das funções ma- ternas - o convívio e o cuidado com os filhos - foi referido como possível, natural, tolerável e por vezes prazeroso para as entrevistadas. Elas comentaram sobre irritações com as crianças, mas de forma geral, fizeram poucas queixas quanto às demandas de trabalho com elas.

A procura ou manutenção dos relacionamentos amorosos pareceu constante nas entrevistadas, no segundo momento do estudo. Nos depoimentos, não houve maiores indicadores de promiscuidade sexual, mas sim de experiências sexuais sem necessária continuidade de envolvimento amoroso, quando as que não estavam com os companheiros "ficavam" com rapazes. Principalmente as entrevistadas que estavam com seus companheiros sugeriram melhorias nas relações sexuais, dispondo de maior conhecimento do próprio corpo e o do parceiro.

Passados cerca de quatro anos da primeira gravidez ocorrida na adolescência, todas as entrevistadas pareceram passar por dificuldades no uso de métodos contraceptivos, fosse por uso inadequado ou por sintomas colaterais. Interessantemente, algumas sugeriram que as adolescentes "atuais" ("de hoje em dia") tinham mais condições do que elas para evitar a gravidez, comentando sobre o aumento da veiculação da temática sexual em programas de televisão. Uma tentativa e uma realização de aborto com utilização de Cytotec ${ }^{\circledR}$ (Misoprostol) foram citadas nos depoimento de duas entrevistadas, com procedimentos feitos por elas mesmas e em suas casas. Três das oito entrevistadas já tinham um segundo filho quando na segunda etapa da sequência longitudinal.

No segundo estudo, as entrevistadas indicaram manter com os companheiros a mesma linha de relacionamento apresentada no primeiro momento. Duas das entrevistadas mantiveram-se junto dos companheiros e duas separaram-se e reataram o relacionamento, voltando a morar junto. Nesses casos, as crianças tinham o nome do pai nos registros de nascimento. Os relatos sobre os pais das crianças indicaram que aqueles que continuavam no convívio com os filhos pareciam desenvolver-se nas funções paternas de cuidado e responsabilidade, de forma semelhante aos achados de Trindade e Menandro (2002), em seus estudos sobre pais (homens) adolescentes. Entretanto, se comparadas com eles, as entrevistadas pareciam ter maior proximidade, sensação de dever e poder de autoridade sobre as crianças.

Mesmo vivendo situações inseguras (até com riscos de sobrevivência), as entrevistadas que apresenta- 
ram condições melhores de amadurecimento foram as que melhor estavam se relacionando com suas famílias de origem e com seus companheiros. Elas indicaram possuir esperança e alegria, relativa capacidade para suportar frustrações e ambivalências, manifestaram alguns sonhos e projetos, e em especial, indicaram recuperação e crescimento após situações de crise. Nesses casos, sempre esteve presente o diferencial de ausência de maior dano relativo a figuras paternas (homens adultos) - por manutenção de bom vínculo, restauro, e reencontro.

\section{CONSIDERAÇÕES FINAIS}

Extrapolando âmbitos domésticos, pessoais e familiares, a gravidez em jovens de zonas pobres urbanas, integra atualmente a pauta de discussões da saúde pública voltada ao atendimento de adolescentes. O fenômeno não fica restrito aos segmentos mais pobres da população, mas é neles que ele é mais frequente $\mathrm{e}$ mais preocupante.

As contribuições de estudos e algumas políticas públicas (como nos programas especializados de prénatal na rede pública de atendimento de saúde), em geral, enfatizam os aspectos prejudiciais da gravidez em adolescentes, considerando riscos de saúde imediatos, relacionados à gravidez e ao parto, e riscos sociais futuros, considerando prejuízos ao desenvolvimento da vida da mãe, do pai e do filho recém-nascido, principalmente ligados à manutenção do estado de pobreza.

Resultados da investigação longitudinal aqui apresentada indicaram que o evento da maternidade ocorrida na adolescência causou ou agravou obstáculos sociais, principalmente os relacionados a uma melhor capacitação escolar para inserção no mercado de trabalho. No entanto, ter filhos e estar com eles, pelo menos enquanto eram pequenos, pode indicar também algum tipo de proteção de natureza psicossocial, especialmente relacionada à convivência, administração e escapes no mundo das drogas, para algumas adolescentes pobres.

Ações públicas voltadas ao enfrentamento do fenômeno urbano da gravidez de adolescentes pobres necessitam superar o mito de um significado negativo, único e exclusivo, dessa procriação. Além da provável criação e ampliação de obstáculos ao desenvolvimento, uma gravidez na adolescência pode significar alguma oportunidade de busca ou encontro de refúgio diante de riscos sociais graves que atingem adolescentes pobres de centros urbanos.
Estando ou não com seus companheiros, junto ou longe de suas famílias de origem, as oito jovens estudadas no seguimento longitudinal, que foram mães na adolescência, tenderam a ficar mais isoladas em casa, até quando seus filhos estavam com aproximadamente quatro anos. Seus filhos estavam fora de creches e elas fora da escola e do mercado de trabalho, embora parecessem também estar, pelo menos por aquele espaço de tempo, um pouco mais protegidas dos riscos relativos à criminalidade e a envolvimento direto com drogas.

\section{REFERÊNCIAS}

Amazarray, M. R., Machado, P. S., Oliveira, V. Z., \& Gomes, W. B. (1998). A experiência de assumir a gestação na adolescência: Um estudo fenomenológico. Psicologia: Reflexão e Crítica, 11, 1-10. Retirado em 30 de julho de 2007, da base de dados SciELO.

Aquino, E. M. L., Heilborn, M. L., Knauth, D., \& Bozon, M. (2003). Adolescência e reprodução no Brasil: A heterogeneidade dos perfis sociais. Cadernos de Saúde Pública, 19, 377-388. Retirado em 6 de maio de 2007, da base de dados SciELO.

Bleger, J. (1989). Temas de psicologia: Entrevista e grupos (4 ${ }^{\mathrm{a}}$ ed.) (R. M. Moraes, Trad.). São Paulo: Martins Fontes.

Borges, A. L. V., \& Schor, N. (2005). Trajetórias afetivoamorosas e perfil reprodutivo de mulheres adolescentes residentes no município de São Paulo (2005). Revista Brasileira de Saúde Materno Infantil, 5, 163-170. Retirado em 30 de julho de 2007, da base de dados SciELO.

Brasil (1997). Resolução no 196 de 10 de outubro de 1996. Diretrizes e Normas Regulamentadoras de Pesquisas Envolvendo Seres Humanos. Ministério da Saúde, Secretaria de Assistência à Saúde, Conselho Nacional de Saúde, Programa Nacional de Doenças Sexualmente Transmissíveis/AIDS. Brasília, 5-18.

Cannon, L. R. C. (1998). Prefácio. Em E. M. Vieira, M. E. L. Fernandes, P. Bailey \& A. McKay (Orgs.), Seminário Gravidez na Adolescência (pp. 11-12). Rio de Janeiro: Ministério de Saúde/Family Health International/Associação Saúde da Família.

Carvalho, J. E. C. (2007). How can a child be a mother? Discourse on teenage pregnancy in a Brazilian favela. Culture, Health \& Sexuality, 9, 109-120.

Esteves, J. R., \& Menandro, P. R. (2005). Trajetórias de vida: Repercussões da maternidade adolescente na biografia de mulheres que viveram tal experiência. Estudos de Psicologia, 10, 363-370. Retirado em 29 de julho de 2007, da base de dados SciELO.

Knobel, M. (1998). O pensamento e a temporalidade na psicanálise da adolescência. Em A. Aberastury (Org.), Adolescência ( $5^{\mathrm{a}}$ ed.) (R. Cabral, Trad.) (pp. 33-72). Porto Alegre: Artes Médicas.

Rodrigues, A. M. (1978). Operário, operária: Estudo exploratório sobre o operariado industrial da Grande São Paulo. São Paulo: Símbolo.

Santos, S. R., \& Schor, N. (2003). Vivências da maternidade na adolescência precoce. Revista de Saúde Pública, 37, 15-23. Retirado em 30 de julho de 2007, da base de dados SciELO. 
Trindade, Z. A. \& Menandro, M. C. S. (2002). Pais adolescentes: Vivência e significação. Estudos de Psicologia, 7, 15-23. Retirado em 30 de maio de 2007, da base de dados SciELO.

\section{Nota:}

${ }^{1}$ Como no estudo inicial, no seguimento longitudinal foram seguidas normas éticas relativas a pesquisas com seres humanos: esclarecimentos sobre a pesquisa, consentimento livre e esclarecido, possibilidade de desistência em qualquer momento da pesquisa e de acesso a contato com a pesquisadora (Brasil, 1997).

\section{Sobre a autora:}

Nancy Ramacciotti de Oliveira-Monteiro: Psicóloga, mestre em Psicologia Social pela Pontifícia Universidade Católica de São Paulo (1984), doutora e pós-doutora em Psicologia Social pela Universidade de São Paulo (1999), é professora do curso de Psicologia da Universidade Federal de São Paulo (UNIFESP), campus da Baixada Santista.

Endereço para correspondência: Av. Washington Luis, 553/51 - Boqueirão - 11055-001 Santos/SP - Endereço eletrônico: nancy.unifesp@gmail.com. 